\section{FRI0493 DISEASE ACTIVITY TOGETHER WITH DEPRESSION CONTRIBUTES TO WORK DISABILITY IN PSORIATIC ARTHRITIS}

F. Farkas ${ }^{1}$, N. Ikumi ${ }^{1}$, A. Szentpetery ${ }^{1}$, B. Kirby ${ }^{2}$, O. FitzGerald ${ }^{1} .{ }^{1}$ Department of Rheumatology; ${ }^{2}$ Department of Dermatology, St. Vincent's University Hospital, Dublin, Ireland, Dublin, Ireland

Background: Work disability (WD) is an important functional outcome measure in inflammatory arthritis, which has been studied comprehensively in rheumatoid arthritis and ankylosing spondylitis, however limited data are available in psoriatic arthritis $(\mathrm{PsA})^{1}$. Depression and anxiety are well known comorbidities in psoriasis and PsA with higher prevalence in PsA ${ }^{2}$.

Objectives: The aim of this study was to compare 1) patient-reported outcomes (PROs), including depression/anxiety scores; 2) physician-assessed measures and 3) disease activity using minimal disease activity (MDA) and Composite Psoriatic Disease Activity Index (CPDAI) in PsA patients with and without WD. Methods: Consecutive patients with PSA fulfilling the CASPAR criteria were enrolled. Patients on disability pension, those with early retirement due to arthritis, those unemployed, away from work due to sick leave were considered as having WD. Patients have completed questionnaires on physical function and health-related quality of life and they were assessed for depression/anxiety using the Hospital Anxiety and Depression Scale (HADS-A and HADS-D) and Penn State Worry Questionnaire (PSWQ). Patients underwent musculoskeletal and skin assessments. Disease activity was compared between work-disabled and employed patients using MDA and CPDAI. Mann-Whitney, Chi-square tests and linear regression model were used to perform statistical analysis.

Results: 100 PsA patients were recruited, 18 were natural retirees, leaving 82 patients available for analysis. Thirty-one (17 male, age $50.9 \pm 9.97$ years) participants of working age had work disability versus fifty-one (29 male, age $49.1 \pm 8.65$ years) employed patients. Work-disabled patients had significantly higher HADS-D score $(5.07 \pm 3.01$ vs. $2.57 \pm 2.64 ; p<0.001)$ and significantly worse PROMs, including HAQ, PsAQoL, EQ-5D, BASDAI, BASFI, ASQoL, BRAF-NRS, pain and general health VAS. HADS-A and PSWQ scores were similar in both groups. Leeds enthesitis index and ESR were significantly higher $(\mathrm{p}=0.008 ; \mathrm{p}=0.04$, respectively) in patients with WD compared to those employed; furthermore the $\%$ of patients with CPDAl $>4$, suggesting moderate to severe disease activity were significantly higher $(51.6 \%$ vs. $28 \% ; p=0.032)$ in the WD group. There was no significant difference in MDA status between the two groups. Multiple regression analysis revealed significant relationship between HADS-D scores and CPDAI $(B=0.566 ; p=0.03)$.

Conclusions: Consistent with previous studies we have observed that the WD rate is high (37.8\%) among patients with PsA. This is the first study assessing the relationship between depression and disease activity using CPDAI in PSA patients with work disability. We have found significantly higher HADS-D score and higher $\%$ of patients with CPDAI $>4$ in the WD group compared to those employed. Significant relationship was revealed between depression and CPDAI, which suggests that disease activity together with depression contributes to work disability in PsA.

References:

[1] Tillett W. Rheumatology (Oxford) 2012.

[2] McDonough E. JRheumatol 2014.

Disclosure of Interest: F. Farkas: None declared, N. Ikumi: None declared, A. Szentpetery: None declared, B. Kirby Grant/research support from: Abbvie, O. FitzGerald Grant/research support from: Abbvie, Pfizer, BMS, Consultant for: Abbvie, Pfizer, BMS, Celgene, Janssen, Novartis, UCB, Eli Lilly

DOI: 10.1136/annrheumdis-2017-eular.5311

\section{FRI0494 SECUKINUMAB PROVIDES RAPID AND SUSTAINED PAIN RELIEF IN PSORIATIC ARTHRITIS: 2-YEAR RESULTS FROM THE FUTURE 2 STUDY}

I.B. Mclnnes ${ }^{1}$, P.J. Mease ${ }^{2}$, G. Schett ${ }^{3}$, B. Kirkham ${ }^{4}$, V. Strand ${ }^{5}$, N. Williams ${ }^{6}$, T. Fox ${ }^{7}$, L. Pricop ${ }^{8}$, S. Jugl ${ }^{7}$, K.K. Gandhi ${ }^{8}$ on behalf of the FUTURE 2 study group. ${ }^{1}$ University of Glasgow, Glasgow, United Kingdom; ${ }^{2}$ Swedish Medical Center and University of Washington, Seattle, United States; ${ }^{3}$ University of Erlangen-Nuremberg, Erlangen, Germany; ${ }^{4}$ Guy's \& St Thomas' NHS Foundation Trust, London, United Kingdom; ${ }^{5}$ Stanford University School of Medicine, Palo Alto; ${ }^{6}$ RTI Health Solutions, Durham, United States: ${ }^{7}$ Novartis Pharma AG, Basel, Switzerland; ${ }^{8}$ Novartis Pharmaceuticals Corp., East Hanover, United States

Background: Pain remains a major clinical challenge in the treatment of psoriatic arthritis (PsA). Secukinumab (SEC) has demonstrated significant efficacy in PsA patients (pts), across a range of quality of life related outcome measures. ${ }^{1,2}$ Objectives: This post-hoc analysis evaluated change in pain scores from baseline (BL) to Week (Wk) 104 in PsA pts receiving SEC in the FUTURE 2 study. Methods: FUTURE 2 study design has been reported. ${ }^{2}$ Mean change from BL in pain VAS and SF-36 bodily pain domain scores were evaluated using mixedeffect model for repeated measures (MMRM) through Wk 16 and as observed through Wk 104. Proportion of pts reporting improvements $\geq$ clinically meaningful differences in pain VAS (mean change from $\mathrm{BL}>20 \%$ ) was assessed. Results are reported for SEC 300 and $150 \mathrm{mg}$ in overall population and stratified by prior use of TNF inhibitor (TNFi; TNFi-naïve vs. inadequate responder/intolerant [TNFi-IR]).
EQ-5D-3L pain item scores (no-, moderate- or extreme-pain/discomfort) were assessed as proportions.

Results: Mean changes from BL in pain VAS were greater with SEC vs. placebo (PBO) by Wk 3 (least squares mean [LSM]: -16.9, -12.6 with SEC 300 and $150 \mathrm{mg}$, respectively vs. -5.75 with PBO; $P<0.05$ ), and Wk 16 (LSM: -24.0 and -23.0 for SEC 300 and $150 \mathrm{mg}$, respectively vs. -8.41 with $\mathrm{PBO} ; P<0.05)$. Mean changes were sustained through Wk $104(-26.1$ and -25.9 with SEC 300 and $150 \mathrm{mg}$, respectively). In both SEC groups, $>50 \%$ pts reported improvements of $\geq 20 \%$ by Wk 3 and this increased through Wk 104. Similarly, SF-36 bodily pain domain scores improved from BL by Wk 4 and 16 with SEC vs. PBO, exceeding minimum clinically important differences of 5.0 (Wk 4: LSM: 16.2 and 16.3 for SEC 300 and $150 \mathrm{mg}$, respectively vs. 5.9 with PBO; $P<0.05$ and Wk 16 : LSM: 21.1 and 22.0 for SEC 300 and $150 \mathrm{mg}$, respectively vs. 6.9 with PBO; $P<0.05$ ). Improvements in pain were consistent in TNFi-naïve and TNFi-IR pts; and of greater magnitude in the naïve subgroup (table). Based on the EQ-5D-3L pain/discomfort item, $99 \%$ pts reported moderate to extreme pain or discomfort at BL. At Wk 4 , the proportion of pts with no pain or discomfort was greater for the SEC $300 \mathrm{mg}(15 \%)$ and $150 \mathrm{mg}(10 \%)$ vs. PBO (5\%) and increased through Wk 104 to $28 \%$ and $16 \%$ with SEC 300 and $150 \mathrm{mg}$, respectively.

Table 1. Summary of results by TNFi status at baseline

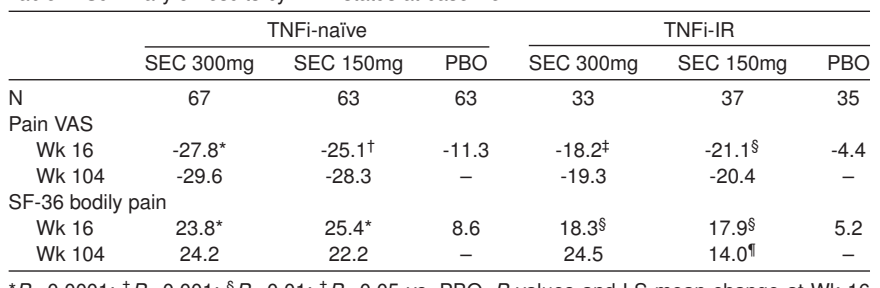
from MMRM analysis. Mean change at Wk 104 from observed data in $n=57(300 \mathrm{mg})$ and 53 $(150 \mathrm{mg})$ for TNFi-naïve and $\mathrm{n}=29$ (300mg) and 24 (150mg) for TNFi-IR; ${ }^{\Uparrow} \mathrm{n}=26$.

Conclusions: SEC provides rapid and sustained pain relief through 104 wks in pts with PsA as assessed by multiple clinically relevant patient-reported measures of pain. Improvements were reported by pts regardless of their prior TNFi therapy status.

References:

[1] Strand V, et al. Ann Rheum Dis 2017;76:203-7.

[2] Mclnnes IB, et al. Lancet 2015;386:1137-46.

Disclosure of Interest: I. McInnes Grant/research support from: AbbVie, Amgen, BMS, Celgene, Janssen, Lilly, Novartis, Pfizer and UCB, Consultant for: AbbVie, Amgen, BMS, Celgene, Janssen, Lilly, Novartis, Pfizer and UCB, Speakers bureau: AbbVie, Amgen, BMS, Celgene, Janssen, Lilly, Novartis, Pfizer and UCB, P. Mease Grant/research support from: Abbvie, Amgen, BMS, Celgene, Crescendo Bioscience, Genentech, Janssen, Lilly, Merck, Novartis, Pfizer, and UCB, Consultant for: Abbvie, Amgen, BMS, Celgene, Crescendo Bioscience, Genentech, Janssen, Lilly, Merck, Novartis, Pfizer, and UCB, Speakers bureau: Abbvie, Amgen, BMS, Celgene, Crescendo Bioscience, Genentech, Janssen, Lilly, Merck, Novartis, Pfizer and UCB, G. Schett: None declared, B. Kirkham Grant/research support from: AbbVie, Eli Lilly, Novartis, Roche and UCB, Consultant for: Abbott, Eli Lilly and Novartis, Speakers bureau: Abbott, Janssen, Novartis and Pfizer, V. Strand Consultant for: AbbVie, Amgen, BMS, Celgene, Celltrion, Corrona, Genentech/Roche, GSK, Janssen, Lilly, Merck, Novartis, Pfizer, Regeneron, Sanofi and UCB, N. Williams Consultant for: Novartis through employment at RTI, Employee of: RTI Health Solutions, T. Fox Shareholder of: Novartis, Employee of: Novartis, L. Pricop Shareholder of: Novartis, Employee of: Novartis, S. Jugl Shareholder of: Novartis, Employee of: Novartis, K. Gandhi Shareholder of: Novartis, Employee of: Novartis

DOI: 10.1136/annrheumdis-2017-eular.5086

\section{FRI0495 USE OF MELATONIN IN PATIENTS WITH PSORIATIC ARTHRITIS VIOLATIONS OF EMOTIONAL STATUS}

I. Blaginina ${ }^{1}$, O. Rebrova ${ }^{1}$, N. Bludova ${ }^{1}, 0$. Volman $^{2}{ }^{1}{ }^{1}$ Internal Medcine, SI "Lugansk State Medical University"; ${ }^{2}$ Lugansk Clinical Regional Hospital, Lugansk, Ukraine

Background: The ability of melatonin to reduce the activity of the sympathetic nervous system tone and of pituitary-adrenal system ensures its anti-stress properties. It can be used to reduce psycho-emotional manifestations of chronic pain in patients with psoriatic arthritis (PsA).

Objectives: To evaluate the effect of combined therapy with the use of melatonin on the expression of psycho-emotional disorders, and pain in patients with PsA. Methods: High levels of anxiety and depressive disorders were established in the survey on Spielberger Anxiety Scale and on Hamilton Rating Scale for Depression (HRDS) in 43 patients with PsA ( $\geq 5 \mathrm{SJC}$ and $\geq 5 \mathrm{TJC}$; CRP $\geq 0.3 \mathrm{mg} / \mathrm{dL}$ ). The quality of life was studied by questionnaire Medical Outcomes Study Short Form (SF-36); the severity of morning stiffness, pain, patient's health status (EWS) - using the 100-mm visual analog scale (VAS). All patients were receiving a stable dose of MTX for at least 6 months. They were divided into two groups; 1 group $(n=22)$ additionally received $3 \mathrm{mg}$ of melatonin at bedtime for 2 months of observation Results: At the end of the observation period the frequency and the level of 
severity of depression by HRDS ( $\mathrm{p}=0.0098)$, and the index of personal anxiety $(\mathrm{P}=0.009)$ in group 1 decreased. In the 2 nd group above mentioned parameters have not changed. On the 1 group data of SF-36 evaluation: the physical health component has improved - the increase of RP and BP $57.4 \%$ and $37.8 \%$ from the baseline; vital activity and role functioning due to emotional state, have also increased by $35.6 \%$ and $43.5 \%$, respectively. In the 2nd group $(n=22)$ investigated parameters have not undergone significant changes in dynamics. In the 1 receiving melatonin group TJC and SJC have decreased by $15 \%$ and $22 \%$ $(p=0.0079, p=0.0022$, respectively) and their dynamics in the 2 nd group was less significant $(p=0.013$ and $p=0.017$, respectively). Also, patients in group 1 have highly significant $(p<0.001)$ reduction in the severity of morning stiffness and joint pain, and in the 2nd group the changes were less significant (respectively, $p=0.043, p=0.016$ ). Positive dynamics of CRP in group 1 was more significant $(p=0.003)$, than it was in 2 patients' group $(p=0.033)$.

Conclusions: In the group of patients treated with melatonin was noted improvement in general condition (a significant improvement in the parameters of the physical components of health, reduction of depressive and psycho-vegetative disorders) and also more significant decrease of the intensity of pain and of morning stiffness duration, of TJC and SJC, than in not treated with melatonin patients. Inclusion of Melatonin in the comprehensive PsA therapy promotes not only reduction of depression symptoms and sleep disorders, but also reduces the severity of the chronic pain manifestations and, consequently, improves the quality of life of patients with this disease

Disclosure of Interest: None declared

DOI: 10.1136/annrheumdis-2017-eular.2378

\section{FRI0496 COMPARING TOFACITINIB SAFETY PROFILE IN PATIENTS WITH PSORIATIC ARTHRITIS IN CLINICAL STUDIES WITH REAL-WORLD DATA}

J.R. Curtis ${ }^{1}$, H. Yun ${ }^{1}$, O. FitzGerald ${ }^{2}$, K. Winthrop ${ }^{3}$, V.F. Azevedo ${ }^{4}$, G. Burmester ${ }^{5}$, W.F.C. Rigby ${ }^{6}$, K.S. Kanik ${ }^{7}$, R. Rojo ${ }^{7}$, S. Menon ${ }^{7}$, C. Wang ${ }^{7}$, P. Biswas ${ }^{8}$, T. Hendrikx ${ }^{9}$, N. Palmetto ${ }^{8} .{ }^{1}$ University of Alabama at Birmingham, Birmingham, AL, United States; ${ }^{2}$ Department of Rheumatology, St Vincent's University Hospital, Dublin, Ireland; ${ }^{3}$ Oregon Health and Science University, Portland, OR, United States; ${ }^{4}$ Universidade Federal do Paraná, Curitiba, Brazil; ${ }^{5}$ Charité - University Medicine Berlin, Berlin, Germany; ${ }^{6}$ Geisel School of Medicine at Dartmouth, Lebanon, NH; ${ }^{7}$ Pfizer Inc, Groton, CT; ${ }^{8}$ Pfizer Inc, New York, NY; ${ }^{9}$ Pfizer Inc, Collegeville, PA, United States

Background: Tofacitinib is an oral Janus kinase inhibitor under investigation for the treatment of psoriatic arthritis (PsA). Two Phase 3 studies have been completed (NCT01877668; NCT01882439) and a long-term extension (LTE) study is ongoing (database not locked; NCT01976364).

Objectives: To compare incidence rates (IR) for adverse events (AEs) of special interest in a tofacitinib cohort from the Phase 3 PsA trials with real-world experience in a comparison cohort from the US Truven MarketScan database.

Methods: The tofacitinib cohort included adult patients (pts) from 2 Phase 3 studies with $>6$ months PsA diagnosis who met CIASsification of Psoriatic ARthritis (CASPAR) criteria, had active plaque psoriasis, and active arthritis $(\geq 3$ swollen and $\geq 3$ tender/painful joints) and who were treated with tofacitinib. Pts were grouped by those who received tofacitinib $5(\mathrm{~N}=238)$ or $10 \mathrm{mg}(\mathrm{N}=236)$ twice daily (BID) in the 2 Phase 3 studies, and all pts who received $\geq 1$ dose of tofacitinib in the 2 Phase 3 studies or the LTE (tofacitinib all doses, N=783). The comparison cohort $(\mathrm{N}=5799)$ comprised pts with moderate to severe PsA, defined by $\geq 1$ inpatient or $\geq 2$ outpatient 696.0 diagnosis codes on 2 unique calendar days ( $\geq 1$ by a rheumatologist) between Oct 2010 and Sep 2015, initiating therapy with a systemic agent for PsA. Key Phase 3 study exclusion criteria were applied to the comparison cohort. IRs for serious infection events (SIEs), herpes zoster $(\mathrm{HZ})$, malignancies (excluding non-melanoma skin cancer [NMSC]), NMSC and major adverse cardiovascular events (MACE) were compared.

Results: Mean age, gender and diabetes history were generally similar between the tofacitinib and comparison cohorts (48.7-49.5 years, $42.4-49.2 \%$ male, $12.2-$ $15.7 \%$ with diabetes history). Overall more pts treated with tofacitinib had prior experience with corticosteroids (15.7-28.2\%), conventional synthetic diseasemodifying antirheumatic drugs (100\%) and tumour necrosis factor inhibitors (48.1-55.9\%) vs the comparison cohort $(11.9 \%, 46.6 \%$ and $36.6 \%$, respectively). IRs for SIEs were lower for the tofacitinib vs the comparison cohort (Table 1). The tofacitinib cohort had a higher rate of $\mathrm{HZ}$ vs the comparison cohort (Table 1). IRs for malignancies and MACE were similar between cohorts (Table 1).

Conclusions: IRs of AEs of special interest reported in tofacitinib PSA Phase 3 studies were generally comparable to those in a general PsA population comprising pts receiving a range of biologic agents, except $\mathrm{HZ}$, which was higher for pts treated with tofacitinb but similar to the incidence observed with tofacitinib treatment in other indications.

Acknowledgements: This study was sponsored by Pfizer Inc. Editorial support was provided by A Pedder of CMC and was funded by Pfizer Inc.

Disclosure of Interest: J. Curtis Grant/research support from: Amgen, BristolMyers Squibb, Eli Lilly, Janssen, Pfizer Inc, Consultant for: AbbVie, Amgen, Bristol-Myers Squibb, Eli Lilly, Janssen, Pfizer Inc, H. Yun Grant/research support from: Pfizer Inc, O. FitzGerald Grant/research support from: AbbVie, Bristol-Myers Squibb, Consultant for: Bristol-Myers Squibb, Eli Lilly, Janssen, Pfizer Inc, Speakers bureau: Celgene, Janssen, Novartis, K. Winthrop Grant/research support

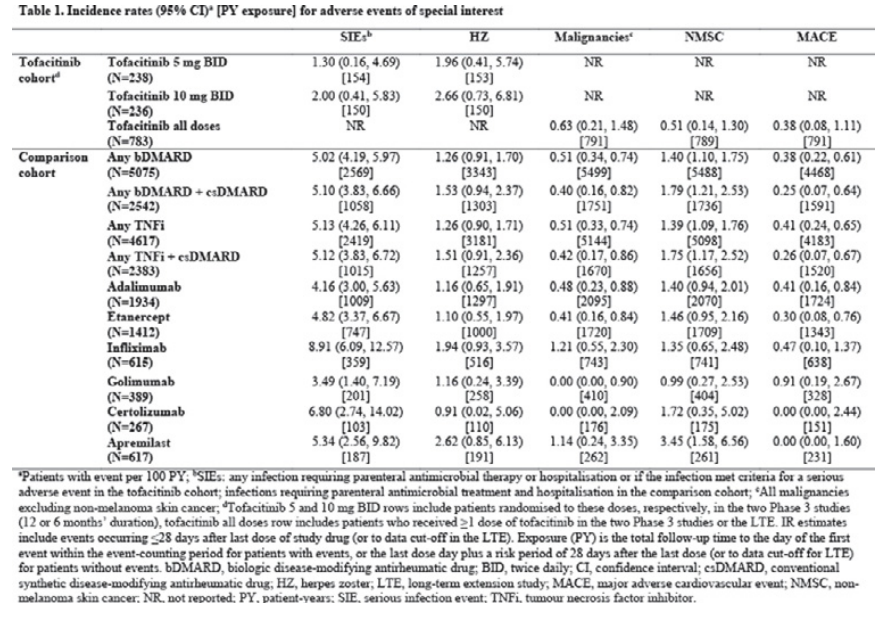

from: Bristol-Myers Squibb, Pfizer Inc, Consultant for: AbbVie, Amgen, BristolMyers Squibb, Eli Lilly, Galapagos, Pfizer Inc, UCB, V. Azevedo Grant/research support from: Bristol-Myers Squibb, GSK, Pfizer Inc, UCB, Consultant for: AbbVie, Bristol-Myers Squibb, Janssen, Merck Serono, Novartis, Pfizer Inc, G. Burmester Grant/research support from: UCB, Consultant for: AbbVie, Bristol-Myers Squibb, Eli Lilly, Hexal, Janssen, MSD, Medimmune, Novartis, Pfizer Inc, Sanofi, Roche, Speakers bureau: AbbVie, Bristol-Myers Squibb, Hexal, MSD, Novartis, Pfizer Inc, Roche, W. F. Rigby Grant/research support from: Amgen, Pfizer Inc, Roche, Consultant for: Bristol-Myers Squibb, Eli Lilly, Pfizer Inc, Roche, K. Kanik Shareholder of: Pfizer Inc, Employee of: Pfizer Inc, R. Rojo Shareholder of: Pfizer Inc, Employee of: Pfizer Inc, S. Menon Shareholder of: Pfizer Inc, Employee of: Pfizer Inc, C. Wang Shareholder of: Pfizer Inc, Employee of: Pfizer Inc, P. Biswas Shareholder of: Pfizer Inc, Employee of: Pfizer Inc, T. Hendrikx Shareholder of: Pfizer Inc, Employee of: Pfizer Inc, N. Palmetto Shareholder of: Pfizer Inc, Employee of: Pfizer Inc

DOI: 10.1136/annrheumdis-2017-eular.2448

\section{FRI0497 WHAT CHOICES DO RHEUMATOLOGIST MAKE IN ESCALATING DMARD THERAPY IN EARLY PSA?}

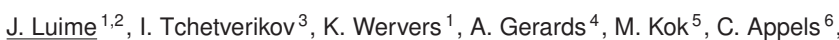
H. van Groenendael ${ }^{7}$, W. vd Graaff ${ }^{8}$, L.-A. Korswagen ${ }^{9}$, J. Veris ${ }^{10}$, M. Hazes ${ }^{1}$, M. Vis ${ }^{1}$ on behalf of Cicero. ${ }^{1}$ Rheumatology, ErasmusMC, Rotterdam; ${ }^{2}$ Data, Analytics and BI, Maxima Medisch Centrum, Veldhoven; ${ }^{3}$ Rheumatology, ASZ, Dordrecht; ${ }^{4}$ Rheumatology, Fransciscus - Vlietland, Schiedam; ${ }^{5}$ Rheumatology, Maasstadziekenhuis, Rotterdam; ${ }^{6}$ Rheumatology, Amphia, Breda;

${ }^{7}$ Rheumatology, Reumazorg zuidwest Nederland, Roosendaal; ${ }^{8}$ Rheumatology, Beatrix ziekenhuis, Gorinchem; ${ }^{9}$ Rheumatology, Franciscus, Rotterdam;

${ }^{10}$ Rheumatology, Reumazorg zuidwest Nederland, Goes, Netherlands

Background: Psoriatic arthritis (PsA) is a multifaceted disease.

Objectives: We aimed to evaluate change in medication over time guided by joints, skin, enthesis, low back pain and dactylitis in newly diagnosed PsA patients Methods: Newly diagnosed PsA patients were included in the Dutch Early south-west Psoriatic Arthritis cohoRt (DEPAR) study between August 2013 and March 2016. Initial drug treatment and escalation of therapy were described for all patients. Drivers of treatment changes in the first year were evaluated by mixed Table 1 Multivariable mixed effects ordered|ordinal logistic regression of treatment change over time in early PsA

Covariates Odds Ratio $95 \% \mathrm{Cl}$

\section{covariates}

Swollen joint count (per joint)
Tender joint count(per joint)
Tender entheses (per enthesis) BASDAI (per point)

Dactylitis Index (per point)

timepoints (baseline reference)

3 months
6 months
9 months
12 months
initial starting values ( no dmard reference)

$$
\begin{aligned}
& 3 \text { months } \\
& 6 \text { months } \\
& 9 \text { months }
\end{aligned}
$$$$
\text { erence) }
$$$$
\text { other sdmards }
$$$$
\text { methotrexate subcutaneous }
$$$$
\text { leflunomide }
$$$$
\text { biolegical dmards* }
$$

mixed effects parameters

random slope random intercept

in bold $\mathbf{p}<0.05$; *biological dmards were TNF inhibitors

$\begin{array}{lll}1.14 & 1.06 & 1.24 \\ 0.98 & 0.94 & 1.02 \\ 1.06 & 0.94 & 1.19 \\ 1.05 & 0.97 & 1.15 \\ 1.05 & 1.00 & 1.09 \\ & & \\ 1.55 & 1.01 & 2.37 \\ 1.25 & 0.78 & 2.02 \\ 0.45 & 0.25 & 0.81 \\ 1.52 & 0.79 & 2.91 \\ & & \\ 0.05 & -0.52 & 0.62 \\ 0.49 & -0.08 & 1.07 \\ 4.67 & 3.95 & 5.38 \\ 5.32 & 4.57 & 6.08 \\ 6.23 & 5.42 & 7.05 \\ & & \\ 0.02 & 0.01 & 0.06 \\ 8.30 & 6.12 & 11.25\end{array}$

